
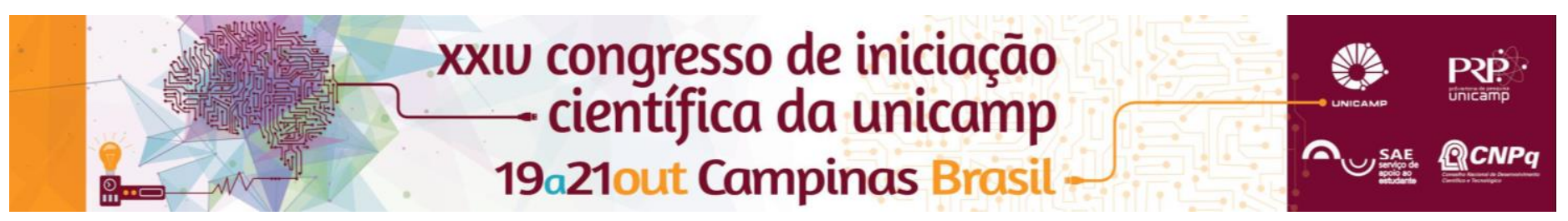

\title{
A utilização de medidas ortodônticas para análise do dimorfismo sexual por meio de imagens por Tomografia Computadorizada de Feixe Cônico.
}

\section{Camila S. Stolf*, Solange M. de Almeida, Henrique M. Martins, Thiago de Oliveira Gamba.}

\section{Resumo}

O presente estudo teve como objetivo avaliar a capacidade de diferenciação sexual de quatro medidas ortodônticas: distância intercanina (DIC), distância intermolar (DIM), espaço requerido (ER) e perímetro do arco dentário (PAD). Essas medidas foram feitas a partir de imagens de Tomografia Computadorizada de Feixe Cônico em 100 pacientes (50 homens e 50 mulheres) previamente atendidos na Clínica de Radiologia Odontológica da FOP-Unicamp. Os arcos dentários foram visualizados nas 3 reconstruções multiplanares (axial, coronal e sagital). As mensurações obtidas foram submetidas a análise estatística do teste t de Student para que se avaliasse o dimorfismo sexual das mesmas. Obteve-se, nas 4 medidas ortodônticas, diferença estatisticamente significante entre homens e mulheres. Pode-se então concluir que as medidas DIC, DIM, ER e PAD podem ser utilizados no estudo do dimorfismo sexual.

\section{Palavras-chave:}

Determinação sexual, crânio, Tomografia Computadorizada de feixe cônico.

\section{Introdução}

A determinação do sexo é considerada como sendo um passo importante para a reconstrução do perfil biológico de um indivíduo desconhecido, e por este fato, o estudo do dimorfismo sexual vem sendo cada vez mais aplicado dentro das ciências forenses. Dessa forma, a pesquisa em questão teve como objetivo avaliar se houve diferença entre as medidas ortodônticas feitas em indivíduos do sexo masculino e indivíduos do sexo feminino.

\section{Resultados e Discussão}

Foi realizado um estudo com 100 imagens, todas do arco dentário superior. As imagens foram avaliadas nas 3 reconstruções multiplanares e as medidas foram feitas pelas ferramentas próprias do software OnDemand3D. Pode-se observar que, nas 4 medidas estudas, há diferença estatisticamente significante entre homens e mulheres, sendo que as medidas ER e PEM apresentam o maior dimorfismo sexual.

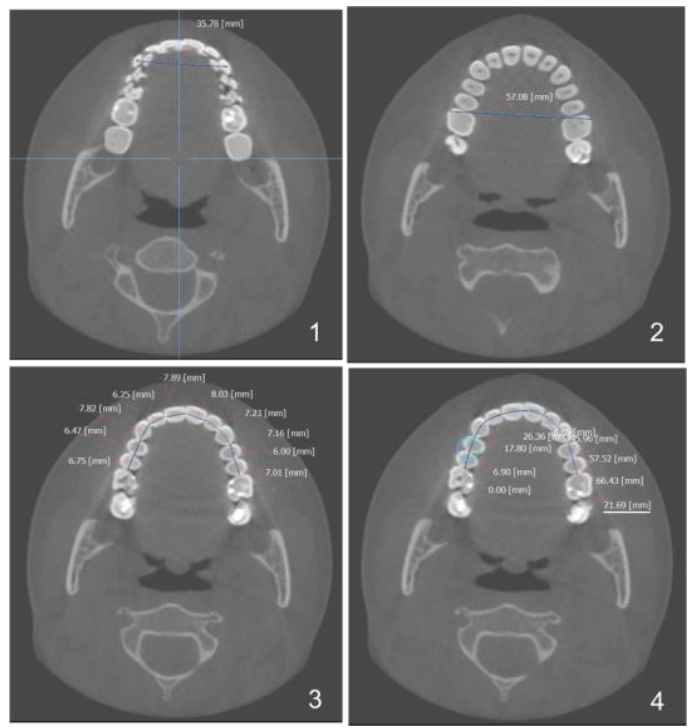

Figura 1: Distancia intercanina (1), distancia intermolar (2), espaço requerido (3) e perímetro do arco (4).
Tabela 1. Análise estatística das medidas ortodônticas.

\begin{tabular}{|c|c|c|c|c|c|}
\hline \multirow[b]{2}{*}{$\begin{array}{c}\text { Medidas } \\
\text { (Arcada Superior) }\end{array}$} & \multicolumn{2}{|c|}{ Homens } & \multicolumn{2}{|c|}{ Mulheres } & \multirow[b]{2}{*}{$\begin{array}{l}\text { Valor } \\
\text { de p }\end{array}$} \\
\hline & $\begin{array}{l}\text { Média } \\
(\mathrm{mm})\end{array}$ & DP & $\begin{array}{l}\text { Média } \\
(\mathrm{mm})\end{array}$ & DP & \\
\hline $\begin{array}{c}\text { Distância Inter } \\
\text { Canina }\end{array}$ & 33.70 & 1.87 & 32.36 & 1.93 & 0.0011 \\
\hline $\begin{array}{c}\text { Distância Inter } \\
\text { Molar }\end{array}$ & 54.15 & 2.85 & 51.77 & 2.77 & 0.0003 \\
\hline $\begin{array}{c}\text { Espaço } \\
\text { Requerido }\end{array}$ & 66.14 & 5.42 & 59.49 & 4.65 & $<0.0001$ \\
\hline $\begin{array}{l}\text { Perímetro do } \\
\text { Arco Dentário }\end{array}$ & 74.52 & 3.82 & 70.51 & 3.96 & $<0.0001$ \\
\hline
\end{tabular}

Desvio padrão (DP)

\section{Conclusões}

Pode-se concluir que as medidas ortodônticas avaliadas no presente estudo têm capacidade de diferenciação sexual e, portanto, podem ser utilizadas no estudo do dimorfismo sexual.

\footnotetext{
1 Kharoshah MA, Almadani O, Ghaleb SS, Zaki MK, Fattah YA. Sexua dimorphism of the mandible in a modern Egyptian population. J Forensic Leg Med 2010;17:213-15.

${ }^{2}$ El Morsi DA, Al Hawary AA. Sex determination by the length of metacarpals and phalanges: X-ray study on Egyptian population. J Forensic Leg Med 2013;20:6-13.

3 Zorba E, Moraitis K, Manolis SK. Sexual dimorphism in permanent teeth of modern Greeks. Forensic Sci Int 2011;210:74-81.

4 Papaloucas C, Fiska A, Demetriou T. Sexual dimorphism of the hip joint in Greeks. Forensic Sci Int 2008;179:1-83.

5 Walker PL. Sexing skulls using discriminant function analysis of visually assessed traits. Am J Phys Anthropol 2008;136:39-50.

${ }^{6}$ Gamba TO, Oliveira ML, Flores IL, Cruz AD, Almeida SM, Haiter-Neto F, Lopes SL. Influence of cone-beam computed tomography image artifacts on the determination of dental arch measurements. Angle Orthod. 2014 Mar;84(2):274-8.
} 